\title{
The Modulation of Motility of Pyloric Antral Smooth Muscles of Rat by Melatonin
}

\author{
Sang Hoon $\mathrm{HAN}^{1}$, Da Woon $\mathrm{LeE}^{1}$, Soo Hyun $\mathrm{CHO}^{2, *}$, and June Sun $\mathrm{KIM}^{3}$ \\ ${ }^{1}$ Departments of Physiology, ${ }^{2}$ Family Medicine, College of Medicine, Chung-Ang University, Seoul 156-756, \\ ${ }^{3}$ Department of Physical Therapy, College of Health Science, Korea University, Seoul 136-703, Republic of Korea
}

(Received February 18, 2010; Accepted April 6, 2010)

\begin{abstract}
Recently some researches have established that the melatonin, secreted by pineal gland, may evoke the changes of contractile responses on smooth muscles. We examined the effects of melatonin on the motility of rat pyloric antrum and which mechanism might be involved in the effects. Pyloric antral strips from the stomach of 20 Sprague-Dawley rats were prepared for isometric tension recording in organ bath. The strips were precontracted by acetylcholine and high- $\mathrm{KCl}$ solutions. In precontracted conditions the tensions were increased by accumulative application of melatonin $\left(10^{-8}-10^{-4} \mathrm{M}\right)$ dose-dependently, even in resting states. And the effects were almost disappeared when the concentrations of ACh were over than $10 \mu \mathrm{M}$. The effects of melatonin were inhibited by pretreatment of $10 \mathrm{mM}$ TEA and/or $10 \mu \mathrm{M}$ 4-AP and rarely affected by pretreatment of $1 \mathrm{mM}$ TEA, $10 \mu \mathrm{M}$ glibenclamide and $10 \mu \mathrm{M}$ verapamil respectively. From these results it is concluded that the contractile responses of smooth muscles of rat pyloric antrum were enhanced by melatonin application and the mechanism might be concerned with the inhibition of some voltage-dependent potassium channels.
\end{abstract}

Keywords: Melatonin, Smooth muscle, Pyloric antrum, Potassium channel

\section{INTRODUCTION}

First demonstration of melatonin receptor binding reactions was introduced from arterial smooth muscle (Viswanathan et al., 1990); there was an increased interest in the study of melatonin actions on the contractile responses of smooth muscle. So contractile responses to melatonin have been reported in many smooth muscles (Doolen et al., 1998; Wang et al., 2002; Poon et al., 2003; Sharkey et al., 2009).

Melatonin, a monoamine hormone secreted by the pineal gland, known as a strong antioxidant (Reiter, 1997) and its secretions are dependent to hypoglycemia and darkness (Liu et al., 1999). This endogenous substance levels are found to decline with age. Although it is well recognized that the pineal gland is associated with controlling circadian rhythm and reproductive function, the definite function of the pineal gland is not elucidated. The interest in melatonin in pineal gland is increasing because it plays a pivotal

${ }^{*}$ Corresponding author

Tel: +82-2-820-5687 Fax: +82-2-817-7115

E-mail: heeyun@cau.ac.kr role in rhythmical control of each organ in human and animals (Reiter, 1993).

The previous investigation reported that oral administrations with melatonin delayed the gastric emptying via cholecystokinin and serotonin, suggesting melatonin has a physiological activity in gastrointestinal motility (Kasimay et al., 2005). Moreover, it was reported that melatonin has effectiveness in modulating hyper-motility in irritable bowel syndrome (Thor et al., 2007). Melatonin ameliorates a decreasing motility of urinary bladder in ageing, which indicates that melatonin may also increase motility in smooth muscle (Gomez-Pinilla et al., 2008).

This study aimed at investigating the physiological role of melatonin in smooth muscle motility. We used pyloric antrum tissue in rat stomach, in which the physiological properties of contraction and relaxation are well known (Mitra and Morad, 1985). We observed the effect of melatonin on response in smooth muscle with relaxing or contracting drug and studied how the effect exerted in this experiment. 


\section{MATERIALS AND METHODS}

\section{Preparation of rat bladder strips and tension measuring}

A total of 20 Sprague-Dawley rats weighing 150-200 g were used throughout this study. All protocols were performed in accordance with the recommendations of the ethic Committee for the Protection of Persons and Animals at the Institute of Medical Science, Chung Ang University, Seoul and Korea. The rats were blacked out by infusion into a tight container with $100 \% \mathrm{CO}_{2}$ gas for $30 \mathrm{sec}$, and were then sacrificed by a cut to the carotid artery. Abdomen was cut and opened the pyloric antral portion of stomach was surgically removed and transferred to a Petri dish containing HEPES buffered physiological salt solution (PSS; composition in mM: $\mathrm{NaCl} 140, \mathrm{KCl} 4, \mathrm{CaCl}_{2} 2, \mathrm{MgCl}_{2}$ 1, $\mathrm{NaHPO}_{4}$ 1.2, L-glucose 11, HEPES $5, \mathrm{pH}$ adjusted to 7.4 with $\mathrm{NaOH}$ ) with $100 \% \mathrm{O}_{2}$ saturation. The strips were then trimmed to $2 \times 2 \times 6 \mathrm{~mm}$.

The strips were mounted in $20 \mathrm{ml}$ organ bath filled with bicarbonate buffered PSS (composition in $\mathrm{mM}$ : $\mathrm{NaCl} 114$, $\mathrm{NaHCO}_{3} 26, \mathrm{KCl} 4, \mathrm{CaCl}_{2} 2, \mathrm{MgCl}_{2}$ 1, $\mathrm{NaHPO}_{4}$ 1.2, L-glucose $11, \mathrm{pH}$ adjusted to 7.4 with $\mathrm{HCl}$ ). The solution in the bath was bubbled with mixed gas $\left(95 \% \mathrm{O}_{2}, 5 \% \mathrm{CO}_{2}\right)$ and maintained at $37^{\circ} \mathrm{C}$ and was exchanged at 30 min intervals. The strips were connected to an isometric force transducer (52-9545, Harvard, UK) and the measurements were recorded on a MacLab 4e recording system (ADInstruments, Australia). Resting tension was adjusted $0.2 \mathrm{~g}$ over $60 \mathrm{~min}$ for equilibration period.

\section{Contractile responses of the strips}

Dose-dependent response of melatonin: At resting status the concentration-dependent responses were observed by adding successive logarithmic increments of melatonin $\left(10^{-8}-10^{-4} \mathrm{M}\right)$.

Dose-dependent response of melatonin on acetylcholine $\left(10^{-5} \mathrm{M}, \mathbf{1 0}^{-6} \mathrm{M}\right)$ pretreated strips: After pretreatment with $10^{-6} \mathrm{M}$ acetylcholine for $5 \mathrm{~min}$ on strips in the organ bath, the strips were contracted and then concentration-dependent responses were determined by adding successive logarithmic increments of melatonin $\left(10^{-9}\right.$. $\left.10^{-4} \mathrm{M}\right)$.

Dose-dependent response of melatonin on $\mathrm{KCl}(35$ $\mathrm{mM}$ ) pretreated strips: After pretreatment with $35 \mathrm{mM} \mathrm{KCl}$ for 5 min on strips in the organ bath, the strips were contracted and then concentration-dependent responses were determined by adding successive logarithmic increments of melatonin $\left(10^{-9}-10^{-4} \mathrm{M}\right)$.

\section{The mechanism of melatonin response}

Various potassium channel blockers $(1 \mathrm{mM}$ tetraethyl ammonium (TEA), $10 \mathrm{mM}$ TEA, $10^{-5} \mathrm{M}$ 4-aminopyridine, $10^{-5} \mathrm{M}$ glibenclamide) and calcium channel blocker $\left(10^{-5}\right.$ $M$ verapamil) were pretreated on strips, the dose-dependent responses for each agent were determined by adding successive logarithmic increments of melatonin $\left(10^{-9}\right.$ $\left.10^{-4} \mathrm{M}\right)$.

\section{Solutions and reagents}

Bicarbonate buffered PSS was used for all the organ bath studies, and HEPES buffered PSS was used for the procedures of tissue preparation. Melatonin was dissolved in dimethyl sulfoxide, and the final concentration was lower than $0.1 \%$ when added the organ bath. Vehicle $(0.1 \%$ dimethyl sulfoxide) was tested, and there was no remarkable change. All chemicals were obtained from Sigma Chemical Company (USA).

\section{Statistical analysis}

The results were obtained after more than 5 replicates of the experiments with same protocol and similar results and representative data are described. Statistical analysis of the data was performed by Student's $t$-test and ANOVA. The results were considered statistically significant at $p$ $<0.05$.

\section{RESULTS}

\section{Effects of melatonin on the basal state}

Application of melatonin $\left(10^{-8}-10^{-4} \mathrm{M}\right)$ to strips on the basal state evoked dose-dependent contractile responses (Fig. 1).

\section{Effects of melatonin on acetylcholine $\left(10^{-5}\right.$ and $\left.10^{-6} \mathrm{M}\right)$ pretreated strips}

The strips were precontracted with $10^{-5}$ or $10^{-6} \mathrm{M}$ acetylcholine and reacted with melatonin $\left(10^{-8}-10^{-4} \mathrm{M}\right)$ in the same bath. At the $10^{-5} \mathrm{M}$ pretreated strips melatonin evoked any remarkable change (Fig. 2). But at the $10^{-6} \mathrm{M}$ pretreated strips melatonin induced dose-dependent contractile responses (Fig. 3).

\section{Effects of melatonin on $\mathrm{KCl}(35 \mathrm{mM})$ pretreated strips}

The strips were pre-treated with $35 \mathrm{mM} \mathrm{KCl}$ and then reacted with melatonin $\left(10^{-8}-10^{-4} \mathrm{M}\right)$, evoking dose-dependent contractions (Fig. 4). 


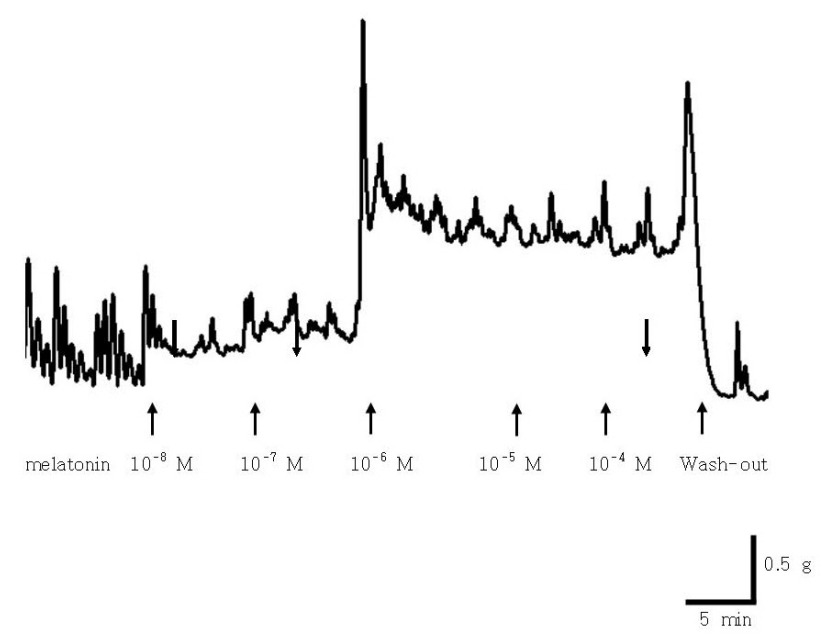

Fig. 1. Typical representation of melatonin-induced response of rat gastric antral strip. Melatonin evoked dose-dependent contracture.

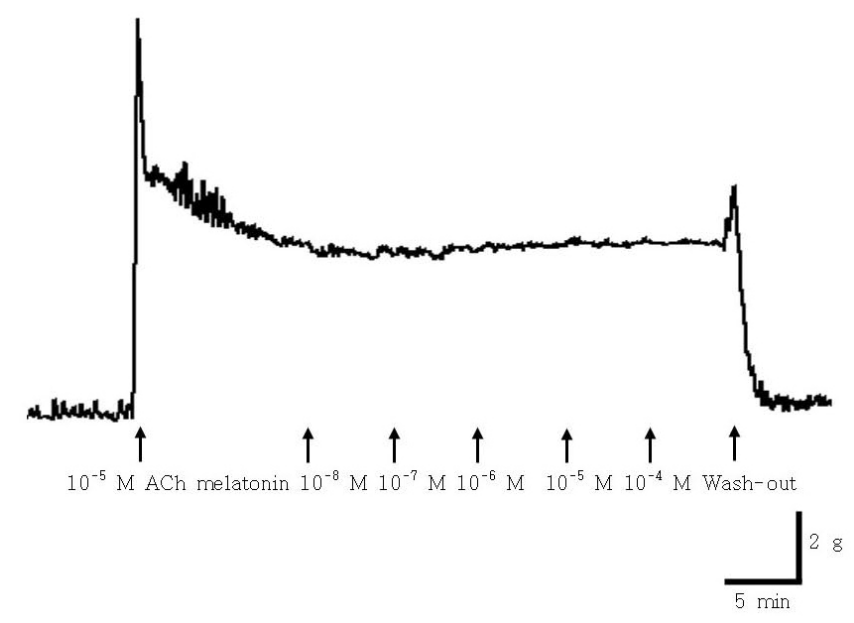

Fig. 2. Typical representation of melatonin-induced response of rat gastric antral strip on the $10^{-5} \mathrm{M}$ acetylcholine (ACh)induced contracture. No remarkable change was detected.

\section{Effects of ion channel blockers on the effects of melatonin}

To determine the mechanisms of the contractile responses of melatonin, the strips were reacted with the various potassium channel blockers, TEA (1 $\mathrm{mM}$ and $10 \mathrm{mM})$, 4-AP $\left(10^{-5} \mathrm{M}\right)$ and glibenclamide $\left(10^{-5} \mathrm{M}\right)$. Some potassium channel blockers ( $1 \mathrm{mM}$ TEA and $10^{-5} \mathrm{M}$ glibenclamide) were failed to evoke any remarkable changes on the melatonin effects, but the others (10 mM TEA and $10^{-5} \mathrm{M}$ 4-AP) were significantly inhibited the responses (Fig. 5). The calcium channel blocker $\left(10^{-6} \mathrm{M}\right.$ verapamil) pretreatment did not evoke any remarkable change (Fig. 6).

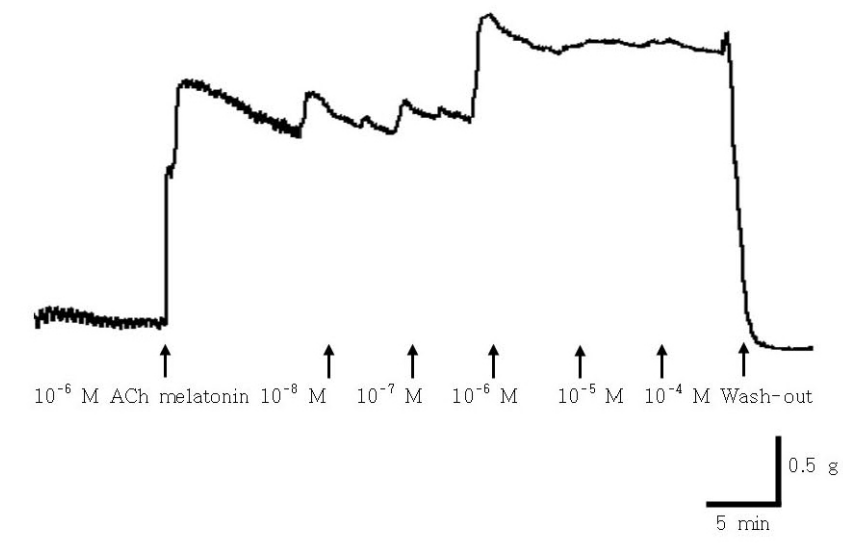

Fig. 3. Typical representation of melatonin-induced response of rat gastric antral strip on the $10^{-6} \mathrm{M}$ acetylcholine (ACh)induced contracture. No remarkable change was detected. The concomitant application of melatonin evoked dose dependent contraction.

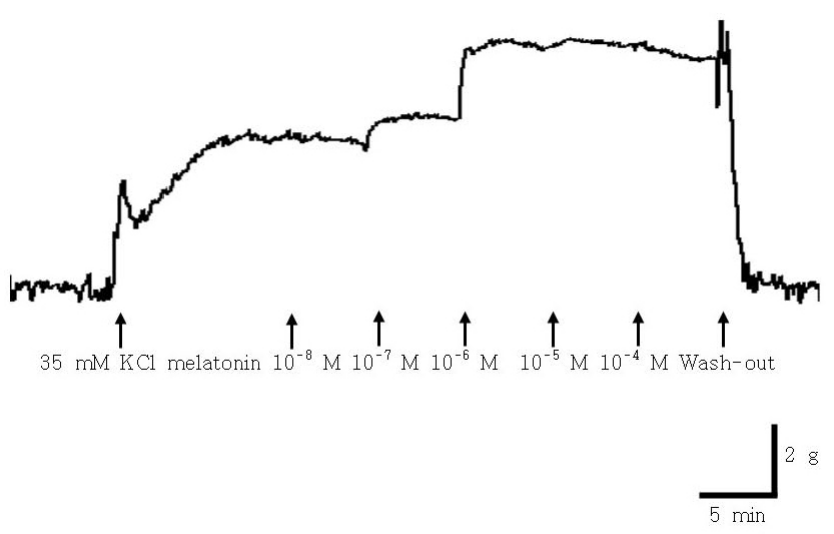

Fig. 4. Typical representation of melatonin-induced response of rat gastric antral strip on the $35 \mathrm{mM} \mathrm{KCl}$-induced contracture. The concomitant application of melatonin evoked dose dependent contraction.

\section{DISCUSSION}

Smooth muscles can be classified according to their characteristics (structure, physiology and neural distribution of electricity, etc.), it is very difficult work to explain general properties of special smooth muscle because of the various characteristics. In general smooth muscle in gastrointestinal, urinary and reproductive systems belongs to phasic smooth muscle, which is excited by the slow waves and results in contraction. Other parts of the sphincters, vascular smooth muscle and airway smooth muscle belong to the tonic smooth muscle, and the level of tonic 


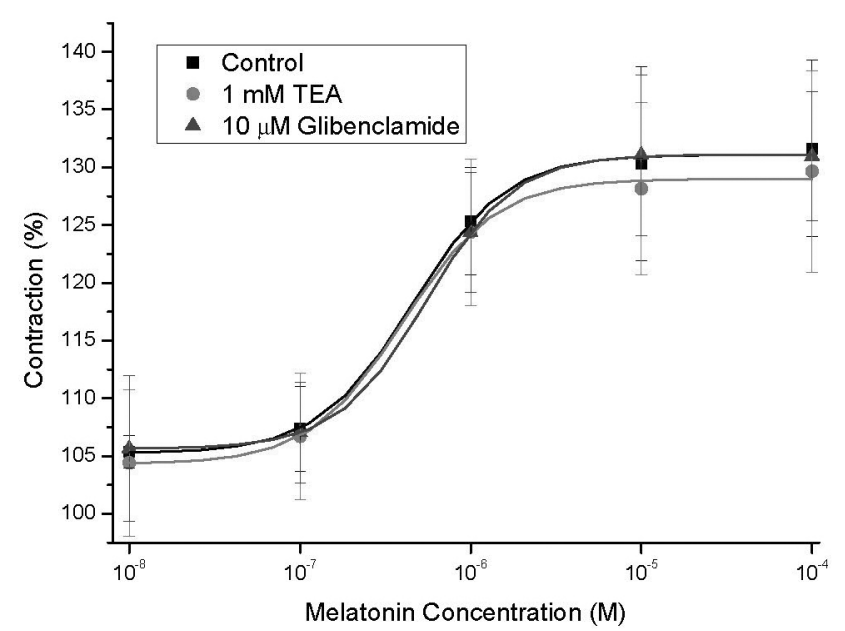

Fig. 5. Dose-dependent relations of melatonin-induced response of rat gastric antral strip on the $1 \mu \mathrm{m}$ ACh-induced contracture. The pretreatment of $1 \mathrm{mM}$ TEA and $10 \mu \mathrm{M}$ glibenclamide rarely affected the response $(n=8)$.

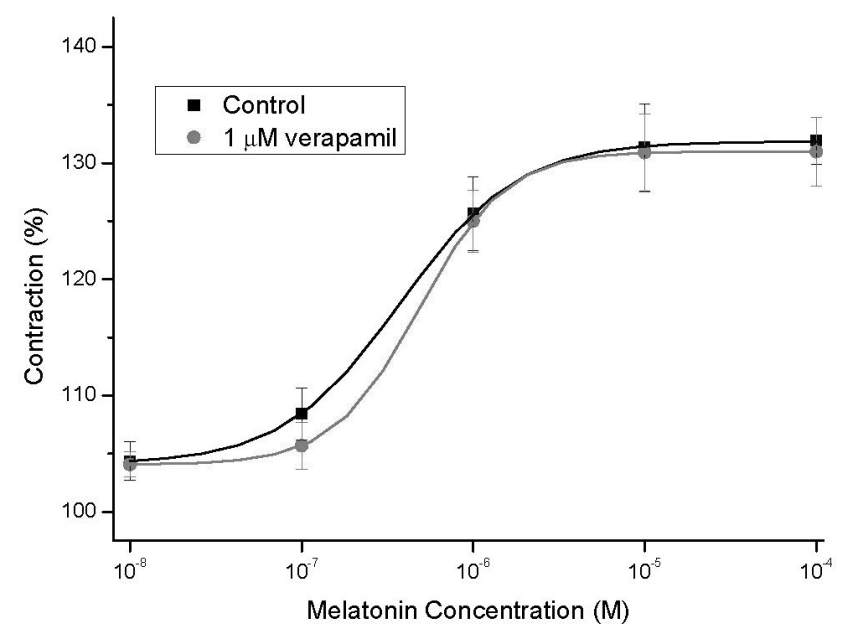

Fig. 6. Dose-dependent relations of melatonin-induced response of rat gastric antral strip on the $1 \mu \mathrm{m}$ ACh-induced contracture. The pretreatment of $1 \mu \mathrm{M}$ verapamil rarely affected the relation $(n=8)$.

contraction is proportional to the membrane potential (Hille, 1992). However, two types of contraction of smooth muscle cells can be regulated by a common molecular mechanism, and all types of smooth muscle cells appear to be potentially capable of both phasic and tonic contractions (Somlyo and Somlyo, 1994). Although these functional regulations of smooth muscle activity are controlled by the autonomic nervous system, smooth muscle is also regulated by various components and endocrine substances (hormones) such as melatonin through the blood because smooth muscle exists in the wall of the internal organs.

Melatonin is known as only one type of pineal gland hormones, which detects the daily and seasonal changes in light cycle and is involved in biological rhythms, such as reproductive activities (Motta et al., 1967). Recently, various effects of melatonin on smooth muscle function have been reported. Melatonin increased the effective contraction of the bladder smooth muscle (Gomez-Pinilla et al., 2008), inhibited the contraction of gastrointestinal smooth muscle by suppressing electrical excitability (Merle et al., 2000) and directly inhibited contraction (Reyes-Vázquez et al., 1997). Until now, those results are controversial.

This study on the effects of melatonin on gastrointestinal smooth muscle showed the distinct results, compared to previous reports. First, dose-dependent contractions were found in steady state, which suggests that melatonin could lead to contraction of the gastrointestinal tract at a higher concentration. The effects of melatonin on the contractile status evoked by acetylcholine were also characteristic. When treated with high concentrations of acetylcholine (10 $\mu \mathrm{M}$ or more), the melatonin treatment had little effect on the contraction, whereas the melatonin caused dose-dependent contraction in less concentrations of acetylcholine. In high potassium-induced contraction, melatonin also led to dose-dependent contractions. These results raised two possibilities that the effects of melatonin could be affected by the concentration of acetylcholine and its effects were hidden at the maximum level of acetylcholine- induced contraction.

Among pretreatments with various potassium channel antagonists such as $1 \mathrm{mM}$ TEA, $10 \mathrm{mM}$ TEA, $10 \mu \mathrm{M}$ glibenclamide or $10 \mu \mathrm{M}$ 4-AP (Harvey et al., 1989), the respective effects of melatonin were suppressed only in pretreated by $10 \mathrm{mM}$ TEA or $10 \mu \mathrm{M}$ 4-AP, which suggests that the effects of melatonin is likely to inhibit the voltage- dependent potassium channels. When pretreated with calcium channel antagonist, verapamil, there was no effect of melatonin on the contraction, suggesting that action mechanism of melatonin had no relations with direct inhibition of calcium channel.

These enhanced contractions by melatonin can interfere with movement of gastrointestinal smooth muscle and have potential positive impact at the same time. Therefore, the results of this study will be helpful for partial understanding of the changes in gastrointestinal motility based on the level of melatonin secretion. However, the precise mechanisms require further elucidation. 


\section{ACKNOWLEDGMENTS}

This Research was supported by the Chung-Ang University Research Grants in 2010 to SH Cho.

\section{REFERENCES}

Doolen, S., Krause, D. N., Dubocovich, M. L. and Duckles, S. P. (1998). Melatonin mediates two distinct receptors in vascular smooth muscle. Eur. J. Pharmacol. 345, 67-69.

Gomez-Pinilla, P. J., Gomez, M. F., Swärd, K., Hedlund, P., Hellstrand, P., Camello, P. J., Andersson, K. E. and Pozo, M. J. (2008). Melatonin restores impaired contractility in aged guinea pig urinary bladder. J. Pineal Res. 44, 416-425.

Harvey, A. L., Rowan, E. G. and Anderson, A. J. (1989). Potassium channel blockers and neuronal function. Pflügers Arch. 414, S106-S110.

Hille, B. (1992). Ionic channels of excitable membranes. pp. 119-244. Sinauer, Sunderland.

Kasimay, O., Cakir, B., Devseren, E. and Yegen, B. C. (2005). Exogenous melatonin delays gastric emptying rate in rats: role of $\mathrm{CCK}_{2}$ and $5-\mathrm{HT}_{3}$ receptors. J. Physiol. Pharmacol. 56, 543-553.

Liu, R. Y., Zhou, J. N., van Heerikhuize, J., Hofman, M. A. and Swaab, D. F. (1999). Decreased melatonin levels in postmortem cerebrospinal fluid in relation to aging, Alzheimer's disease, and apolipoprotein E-epsilon4/4 genotype. J. Clin. Endocrinol. Metab. 84, 323-327.

Merle, A., Delagrange, P., Renard, P., Lesieur, D., Cuber, J. C., Roche, M. and Pellissier, S. (2000). Effect of melatonin on motility pattern of small intestine in rats and its inhibition by melatonin receptor antagonist S 22153. J. Pineal Res. 29, 116-124.

Mitra, R. and Morad, M. (1985). $\mathrm{Ca}^{2+}$ and $\mathrm{Ca}^{2+}$-activated $\mathrm{K}^{+}$ currents in mammalian gastric smooth muscle cells. Science 229, 269-272.

Motta, M., Fraschini, F. and Martini, L. (1967). Endocrine effects of pineal gland and of melatonin. Proc. Soc. Exp. Biol. Med. 126, 431-435.

Poon, A. M. S., Kravtsov, G. M. and Pang, S. F. (2003). Receptor-mediated modulation of avian caecal muscle contraction by melatonin: role of tyrosine protein kinase. $J$. Pineal Res. 32, 199-208.

Reiter, R. J. (1993). The melatonin rhythm: both a clock and a calendar. Experimentia 45, 654-664.

Reiter, R. J. (1997). Antioxidant actions of melatonin. Adv. Pharmacol. 38, 103-117.

Reyes-Vázquez, C., Naranjo-Rodríguez, E. B., García-Segoviano, J. A., Trujillo-Santana, J. T. and Prieto-Gómez, B. (1997). Apamin blocks the direct relaxant effect of melatonin on rat ileal smooth muscle. J. Pineal Res. 22, 1-8.

Sharkey, J. T., Puttaramu, R., Word, R. A. and Olcese, J. (2009). Melatonin synergizes with oxytocin to enhance contractility of human myometrial smooth muscle cells. J. Clin. Endocirnol. Metab. 94, 421-427.

Somlyo, A. P. and Somlyo, A. V. (1994). Signal transduction and regulation in smooth muscle. Nature 372, 231-236.

Thor, P. J., Krolczyk, G., Gil, K., Zurowski, D. and Nowak, L. (2007). Melatonin and serotonin effects on gastrointestinal motility. J. Physiol. Pharmacol. 58(Suppl 6), 97-103.

Viswanathan, M., Laitinen, J. T. and Saavedra, J. M. (1990). Expression of melatonin receptors in arteries involved in thermoregulation. Proc. Natl. Acad. Sci. U. S. A. 87, 62006203.

Wang, X. F., Pang, C. S., Pang, S. F. and Wong, T. M. (2002). Melatonin potentiates phenylephrine-stimulated intracellular $\mathrm{Ca}^{2+}$ transient in smooth muscle cell of large aeteries of chick embryo. J. Cardiovas. Pharmacol. 40, 356-362. 